Kuan Win Sen (Orcid ID: 0000-0002-2134-7842)

Kelly Anne-Maree (Orcid ID: 0000-0002-4655-5023)

Jones Peter (Orcid ID: 0000-0003-1560-1186)

1

Treatment and outcome of adult patients with acute asthma in emergency

departments in Australasia, South East Asia and Europe: Are guidelines

followed? AANZDEM / EURODEM study.

\title{
Simon CRAIG
}

Emergency Department, Monash Medical Centre, Clayton, Victoria, Australia and

School of Clinical Sciences at Monash Health, Monash University, Clayton, Victoria,

Australia.

simon.craig@monash.edu

Win Sen KUAN

Emergency Medicine Department, National University Health System, Singapore and

Department of Surgery, Yong Loo Lin School of Medicine, National University of

Singapore.

win_sen_kuan@nuhs.edu.sg

Anne-Maree KELLY

Joseph Epstein Centre for Emergency Medicine Research, Western Health, St

Albans, Victoria, Australia and Department of Medicine, Melbourne Medical School Western Precinct, The University of Melbourne, St. Albans, Victoria, Australia.

anne-maree.kelly@wh.org.au

Oene VAN MEER

Leiden University Medical Center, Leiden, The Netherlands.

ovanmeer@hotmail.com

Justina MOTIEJUNAITE

This is the author manuscript accepted for publication and has undergone full peer review but has not been through the copyediting, typesetting, pagination and proofreading process, which may lead to differences between this version and the Version of Record. Please cite this article as doi: $10.1111 / 1742-6723.13242$

This article is protected by copyright. All rights reserved. 
INSERM, U942, BIOmarkers in CArdioNeuroVAScular diseases, 75010, Paris,

France; APHP, Saint Louis Lariboisière Hospitals, Department of Anesthesiology and

Critical Care, 75010, Paris, France and Lithuanian University of Health Sciences

Kaunas Clinics, Department of Cardiology, Kaunas, Lithuania.

justina.moti@outlook.com

\section{Gerben KEIJZERS}

Department of Emergency Medicine, Gold Coast University Hospital, Gold Coast, Australia; Faculty of Health Sciences and Medicine, Bond University, Gold Coast, Australia and School of Medicine, Griffith University, Gold Coast, Australia.

gkeijzer@bond.edu.au

\section{Peter JONES}

Emergency Department, Auckland City Hospital, Auckland, New Zealand and University of Auckland Department of Surgery, Auckland, New Zealand. peterj@adhb.govt.nz

\section{Richard BODY}

Emergency Department, Central Manchester University Hospitals NHS Foundation Trust, Oxford Road, Manchester; United Kingdome and Cardiovascular Sciences Research Group, the University of Manchester, Manchester, United Kingdom.

Richard.body@manchester.ac.uk

\section{Mehmet KARAMERCAN}

Gazi University, Faculty of Medicine, Emergency Medicine Department, Ankara, Turkey and Istanbul Bagcilar Training and Research Hospital, Department of Emergency Medicine, Istanbul, Turkey.

makaramercan@yahoo.com

This article is protected by copyright. All rights reserved. 


\section{Sharon KLIM}

Joseph Epstein Centre for Emergency Medicine Research, Western Health, St

Albans, Victoria, Australia.

sharon.klim@wh.org.au

Veli-Pekka HARJOLA

Emergency Medicine, University of Helsinki, Department of Emergency Medicine and Services, Helsinki University Hospital, Helsinki, Finland.

veli-pekka.harjola@hus.fi

\section{Franck VERSCHUREN}

Université Catholique de Louvain, Cliniques Universitaires Saint-Luc, Department of Acute Medicine, Brussels, Belgium.

franck.verschuren@uclouvain.be

\section{Anna HOLDGATE}

Department of Emergency Medicine, Liverpool Hospital, Sydney, Australia and University of New South Wales (Southwest Clinical School), Sydney, Australia. anna.holdgate@sswahs.nsw.gov.au

\section{Michael CHRIST}

Department of Emergency Care, Luzerner Kantonsspital, Luzern, Switzerland and Paracelsus Medical University, Nuremberg, Germany.

christ_michael@me.com

\section{Adela GOLEA}

University of Medicine and Pharmacy, Emergency Department of the University County Emergency Hospital Cluj Napoca, Romania.

adeg2810@gmail.com

This article is protected by copyright. All rights reserved. 


\section{Colin A GRAHAM}

Chinese University of Hong Kong, Prince of Wales Hospital, Shatin, Hong Kong SAR.

cagraham@cuhk.edu.hk

Jean CAPSEC

Tours University Hospital, Public Health Department, 37044, Tours, France.

j.capsec@chu-tours.fr

\section{Cinzia BARLETTA}

St. Eugenio Hospital, Department of Emergency Medicine, Rome, Italy. cinziabarletta25@gmail.com

\section{Luis GARCIA-CASTRILLO}

Servicio Urgencias Hospital Marqués de Valdecilla, Santander, Spain. urggrl@humv.es

\section{Said LARIBI}

Tours University, School of Medicine, INSERM U1100; Tours University Hospital, Emergency Medicine Department, 37044, Tours, France.

s.laribi@chu-tours.fr

AANZDEM and EuroDEM study groups (see acknowledgements).

\section{Corresponding author:}

Professor Anne-Maree Kelly

JECEMR

WHCRE, Sunshine Hospital, St Albans 3021 Australia 
Email: anne-maree.kelly@wh.org.au

\section{Word count:}

Abstract: 221

Main text: 1604

References : 24

Tables: 2

On-line appendix : 1

Figures: 0

This article is protected by copyright. All rights reserved. 


\section{ABSTRACT}

Objective: Asthma exacerbations are common presentations to Emergency Departments (ED). Key guideline recommendations for management include administration of inhaled bronchodilators, systemic corticosteroids and titrated oxygen therapy. Our aim was to compare management and outcomes between patients treated for asthma in Europe (EUR) and South East Asia/Australasia (SEA) and compliance with international guidelines.

Methods: In each region, prospective, interrupted time series studies were performed including adult (age >18) patients presenting to ED with the main complaint of dyspnoea during three 72 -hour periods. This was a planned sub-study that included those with an ED primary diagnosis of asthma. Data was collected on demographics, clinical features, treatment in ED, diagnosis, disposition and inhospital outcome. The results of interest were differences in treatment and outcome between EUR and SEA cohorts.

Results: 584 patients were identified from 112 ED (66 EUR and 46 SEA). The cohorts had similar demographics and co-morbidity patters, with $89 \%$ of the cohort having a previous diagnosis of asthma. There were no significant differences in treatment between EUR and SEA patients - inhaled beta-agonists were administered in $86 \%$ of cases, systemic corticosteroids in $66 \%$, oxygen therapy in $44 \%$ and antibiotics in $20 \%$. Two thirds of patients were discharged home from the ED.

This article is protected by copyright. All rights reserved. 
Conclusion: The data suggests that compliance with guideline-recommended therapy in both regions, particularly corticosteroid administration, is suboptimal. It also suggests over-use of antibiotics.

KEYWORDS: Dyspnoea, emergency department, management, asthma, outcome 


\section{INTRODUCTION}

Shortness of breath is a common reason for patients to attend an emergency department (ED).(1) Patients with dyspnoea make up approximately $5 \%$ of all adult ED attendances, but importantly result in over $11 \%$ of ward admissions and nearly $20 \%$ of intensive care unit (ICU) admissions.(2) Research suggests that an acute exacerbation of asthma is responsible for approximately $13 \%$ of adult patients presenting to the ED with dyspnoea.(2)

The initial management of an exacerbation of asthma is well-established and described in several guidelines including those of the National Asthma Council (Australia), Global Initiative for Asthma, the British Thoracic Society and the Scottish Intercollegiate Guidelines Network.(3-6) These guidelines agree that initial management should include assessment of severity, administration of short-acting beta-agonists (SABAs), titrated oxygen therapy, and administration of systemic corticosteroids. Antibiotics are not recommended unless there is clinical or radiological evidence of infection.

For patients with severe exacerbations, or who do not respond to initial treatment, the recommendations for additional therapy are less uniform between guidelines and may include inhaled anticholinergic medication,(7) intravenous administration of magnesium,(8) aminophylline,(9) parenteral beta-agonists,(10) or ketamine,(11) and/or non-invasive or invasive ventilation.(12)

This article is protected by copyright. All rights reserved. 
While there is local data for some regions, there is little comparative data regarding ED management and compliance with key guideline recommendations across regions around the world. The aim of this study is to describe and compare management and outcomes between patients treated for acute exacerbations of asthma in Europe (EUR) and South East Asia/Australasia (SEA), with an emphasis on compliance with international guideline recommendations, both overall and by region.

\section{METHODS}

This is a planned sub-study of two international, multi-centre, prospective, observational, interrupted time series cohort studies. They were designed to evaluate the epidemiology and outcomes of adult patients (age $>18)$ presenting to the ED with shortness of breath as the main complaint. This sub-study focused on those patients who received an ED diagnosis of acute exacerbation of asthma. The European Dyspnoea in Emergency Medicine (EuroDEM) study (NCT02060799) was conducted in 66 European EDs in Belgium $(n=3)$, Finland $(n=5)$, France $(n=5)$, Germany $(n=5)$, Italy $(n=1)$, the Netherlands $(n=16)$, Romania $(n=7)$, Spain $(n=1)$, Turkey $(n=7)$ and United Kingdom $(n=16)$. The AANZDEM study was conducted in 46 Asia-Pacific centres in Australia $(n=33)$, New Zealand $(n=4)$, Singapore $(n=3)$, Hong Kong $(n=4)$ and Malaysia $(n=2)$. The Asia, Australia and New Zealand Dyspnoea in Emergency Medicine (AANZDEM) study methodology has been previously published.(13) The study sample was generated with consecutive patients attending EDs during three study periods of 72 hours in different seasons throughout one year.

This article is protected by copyright. All rights reserved. 
A specifically designed data collection tool was developed by each regional steering committee. Data collected included patient demographics, co-morbidities, mode of arrival, usual medications, initial assessment (clinical assessment and vital signs), investigations performed and results, treatment in the ED, ED diagnosis (diagnosis at ED discharge), outcome after the ED including disposition and in-hospital mortality. Local investigators at each hospital were provided with detailed information and instructions (including a data dictionary) to increase the reliability of data collection.

The outcomes of interest for this study were differences in management and clinical outcomes between EUR and SEA patient cohorts and compliance with guidelinerecommended treatment, overall, by region and by disposition group (as a surrogate for severity). Results are presented as frequencies or as medians with interquartile range (IQR). The Chi-square test or Fisher's Exact test (as appropriate) were used to compare categories. Continuous variables were compared using the t-test (parametric) and the Wilcoxon test (nonparametric). A Bonferroni correction was applied to account for the multiple comparisons undertaken, with a $p$ value of 0.00116 comparable to a $p$ value of 0.05 from a single comparison. Statistical analysis was performed using SAS version 9.1 software (SAS Institute, Cary, NC, USA).

The study was performed in accordance with the Declaration of Helsinki. Ethics committee approvals were obtained for all sites according to local requirements. If 
requested by the local ethics committee, patient consent for data collection was obtained.

\section{RESULTS}

584 patients were studied; 387 from SEA and 197 from EUR. The median age was 45 years and $38 \%$ of patients were male. Median duration of symptoms prior to ED presentation was 2 days (IQR 1-4 days). The demographics of the cohorts were similar, including co-morbidity pattern. Eighty-nine percent of cases had a past history of asthma $(95 \% \mathrm{Cl} 86-91 \%)$ and $18 \%$ were documented to be currently smoking (95\% Cl 15-22\%). Seventy percent of cases reported use of inhaled beta-2 agonists (95\% Cl 66-74\%), however the proportion was significantly higher in the SEA cohort $(75 \%$ vs. $61 \%$; $p<0.01)$. Inhaled corticosteroid use was low $(44 \%, 95 \% \mathrm{Cl}$ $40-49 \%$ ) but not significantly different between cohorts. Oral steroid use was also similar between cohorts $(14 \%, 95 \% \mathrm{Cl} 11-17 \%)$. (Table 1) About a third of patients arrived at ED by ambulance $(32 \%, 95 \% \mathrm{Cl} 28-36 \%)$; similar between the cohorts. Clinical severity (online appendix A) was also similar in the two cohorts.

There were no statistically significant differences in management between the EUR and SEA cohorts. Inhaled SABA were administered in $86 \%(95 \% \mathrm{Cl} 83-89 \%)$ and systemic corticosteroids in $66 \%(95 \% \mathrm{Cl} 61-69 \%)$. Ventilatory support occurred in 14 patients $(2.4 \%, 95 \% \mathrm{Cl} 1.4-4 \%)$ : non-invasive support in 13 and mechanical ventilation in one patient. Antibiotics were administered in $20 \%$ of patients overall (95\% Cl 17-23\%). (Table 2)

This article is protected by copyright. All rights reserved. 
Two thirds of patients were discharged home from the ED (66\%, 95\% CI 62-70\%), 15 $(2.3 \%, 95 \% \mathrm{Cl} 1.4-4 \%)$ were admitted to ICU, and the remainder was transferred to an inpatient ward $(31 \%, 95 \% \mathrm{Cl} 27-35 \%)$. In total, there was one death $(0.2 \%, 95 \%$ $\mathrm{Cl} 0.03-1 \%)$, occurring in the European cohort.

\section{DISCUSSION}

This study explores the treatment and outcomes of adult patients presenting to ED with acute dyspnea due to asthma exacerbations across two major global regions. Our findings suggest that compliance with guideline-recommended treatment is similar between the regions but that it is sub-optimal, particularly under-use of systemic corticosteroids and potential over-use of antibiotics.

Early administration of systemic corticosteroids has been shown to reduce the need for hospital admission in ED patients with asthma,(13) and is an established component of acute asthma management. It is unclear why one third of patients presenting with an acute exacerbation of asthma including $25 \%$ of those who were admitted to hospital were not administered systemic steroids, and this may be a focus for further research. Possible reasons include very mild disease only requiring reliever medication and/or prehospital administration of corticosteroids by ambulance paramedics or general practitioners. The data available did not allow us to test these hypotheses.

It is notable, also, that approximately $20 \%$ of patients in the cohorts were given antibiotics, increasing to approximately $40 \%$ in admitted patients. The reasons for 
this are unclear. In most cases, asthma exacerbations are due to viral rather than bacterial pathogens.(14) Unnecessary or excessive use of antibiotics for asthma has been documented in various settings, including the USA(15) and Kuwait(16). A recent large study of adult patients with exacerbations of asthma found that the addition of azithromycin to usual treatment did not result in any clinical benefit.(17) Interestingly, a significant proportion of patients screened for eligibility in that study were excluded due to prior initiation of antibiotics,(18) suggesting that antibiotic overuse is a widespread problem in this setting.

Poor compliance with evidence-based asthma guidelines has been noted in both adult and paediatric populations - across many settings.(15, 16, 19, 20) Attempts to improve the quality of asthma care include clinical pathways, treatment protocols, and computerized asthma management systems.(21-23) To date, these interventions have, for the most part, been implemented in paediatric ED, with varying results.

That almost $20 \%$ of patients overall are smokers is of concern as it reduces the effectiveness of inhaled steroids and increases the risk of hospital admission.(24) Also concerning is the low use of regular inhaled corticosteroids. This study was not designed to assess reasons for this, but they may include limired access to primary health care or poor compliance. We did not have access to data on what proportion of patients had asthma action plans. That a low proportion of patients reported taking oral steroids at presentation is suggestive that the proportion with action plans was low and/or that patients did not known when or how to implement them.

This article is protected by copyright. All rights reserved. 
Our study has some limitations that should be considered while interpreting our results. We have combined two datasets, one from Europe and one from the Asia/ Pacific region, which differed slightly in design. This has led to some minor differences in data collection, however we do not consider that this significantly influenced our findings. The size of the cohort and the diversity of ED is a strength of the study as it supports the generalizability of our findings. Data on some specific aspects related to asthma management were not collected due to the nature of the parent study including the use of inhaled anticholinergic medications, the choice of inhalation therapy between hand-held inhaler and nebulizer therapy and the use of intravenous bronchodilator medication such as aminophylline and magnesium administration. We consider this a minor weakness as our intention was to focus on widely accepted, core management. We were also unable to analyse treatment stratified by severity, as this data was not collected in the parent study. There is also a small amount of missing data from some patients, however, this is unlikely to have influenced our results. The sample was defined by the final ED diagnosis which may have been subject to miscoding or error. This pragmatic approach reflects real-world practice.

\section{CONCLUSION}

The data suggests that compliance with guideline-recommended therapy in both regions, particularly corticosteroid administration, is suboptimal. It also suggests over-use of antibiotics. Further efforts to improve and sustain compliance with existing treatment guidelines are required.

This article is protected by copyright. All rights reserved. 
This article is protected by copyright. All rights reserved. 


\section{REFERENCES}

1. Prekker ME, Feemster LC, Hough CL, Carlbom D, Crothers K, Au DH, et al. The epidemiology and outcome of prehospital respiratory distress. Acad Emerg Med 2014;21:543-50.

2. Kelly AM, Keijzers G, Klim S, Graham CA, Craig S, Kuan WS, et al. An Observational Study of Dyspnea in Emergency Departments: The Asia, Australia, and New Zealand Dyspnea in Emergency Departments Study (AANZDEM). Acad Emerg Med 2017;24:328-36.

3. British guideline on the management of asthma. Thorax. 2014;69 Suppl 1:1192.

4. National Asthma Council Australia. Australian Asthma Handbook, Version 1.2. National Asthma Council Australia, Melbourne, 2016.

http://www.asthmahandbook.org.au. Accssed July 2018

5. National Asthma Education and Prevention Program, Third Expert Panel on the Diagnosis and Management of Asthma. Expert Panel Report 3: Guidelines for the Diagnosis and Management of Asthma. Bethesda (MD): National Heart, Lung, and Blood Institute (US); 2007 Aug. https://www.ncbi.nlm.nih.gov/books/NBK7232/. Accessed July 2018

6. GINA (Global Initative for Asthma) Report, Global Strategy for Asthma Management and Prevention. 2016. http://www.ginasthma.org Accsssed September 2016. .

7. Vezina K, Chauhan BF, Ducharme FM. Inhaled anticholinergics and shortacting beta(2)-agonists versus short-acting beta2-agonists alone for children with acute asthma in hospital. Cochrane Database Syst Rev. 2014(7):Cd010283.

8. Kew KM, Kirtchuk L, Michell $\mathrm{Cl}$. Intravenous magnesium sulfate for treating adults with acute asthma in the emergency department. Cochrane Database Syst Rev. 2014;5:CD010909.

9. Nair P, Milan SJ, Rowe BH. Addition of intravenous aminophylline to inhaled beta(2)-agonists in adults with acute asthma. Cochrane Database Syst Rev.

2012;12:CD002742.

This article is protected by copyright. All rights reserved. 
10. Travers AH, Milan SJ, Jones AP, Camargo CA, Jr., Rowe BH. Addition of intravenous beta(2)-agonists to inhaled beta(2)-agonists for acute asthma. Cochrane Database Syst Rev. 2012;12:Cd010179.

11. Goyal S, Agrawal A. Ketamine in status asthmaticus: A review. Indian J Crit Care Med 2013;17:154-61.

12. Pallin M, Naughton MT. Noninvasive ventilation in acute asthma. J Crit Care. 2014;29:586-93.

13. Rowe BH, Spooner C, Ducharme FM, Bretzlaff JA, Bota GW. Early emergency department treatment of acute asthma with systemic corticosteroids. The Cochrane database of systematic reviews. 2001(1):Cd002178.

14. Johnston SL, Pattemore PK, Sanderson G, Smith S, Campbell MJ, Josephs LK, et al. The relationship between upper respiratory infections and hospital admissions for asthma: a time-trend analysis. Am J Resp Crit Care Med 1996;154(3 Pt 1):654-60.

15. Vanderweil SG, Tsai CL, Pelletier AJ, Espinola JA, Sullivan AF, Blumenthal $D$, et al. Inappropriate use of antibiotics for acute asthma in United States emergency departments. Acad Emerg Med 2008;15:736-43.

16. Hijazi Z, Abdulmalek AK, Al-Taweel F, Al-Shareda S. Hospital management of children with acute asthma exacerbations in Kuwait: adherence to international guidelines. Med Princ Pract. 2002;11:126-30.

17. Johnston SL, Szigeti M, Cross M, Brightling C, Chaudhuri R, Harrison T, et al. Azithromycin for Acute Exacerbations of Asthma : The AZALEA Randomized Clinical Trial. JAMA Int Med. 2016;176:1630-7.

18. Brusselle GG, Van Braeckel E. AZALEA Trial Highlights Antibiotic Overuse in Acute Asthma Attacks. JAMA Int Med. 2016;176:1637-8.

19. Hasegawa K, Chiba T, Hagiwara Y, Watase H, Tsugawa Y, Brown DF, et al. Quality of care for acute asthma in emergency departments in Japan: a multicenter observational study. J Allergy Clin Immunol Pract. 2013;1:509-15.e1-3.

20. Hasegawa K, Sullivan AF, Tsugawa Y, Turner SJ, Massaro S, Clark S, et al. Comparison of US emergency department acute asthma care quality: 1997-2001 and 2011-2012. J Allergy Clin Immunol 2015;135:73-80.

This article is protected by copyright. All rights reserved. 
21. Dexheimer JW, Abramo TJ, Arnold DH, Johnson K, Shyr Y, Ye F, et al. Implementation and evaluation of an integrated computerized asthma management system in a pediatric emergency department: a randomized clinical trial. Int J Med Inform 2014;83:805-13.

22. Self TH, Usery JB, Howard-Thompson AM, Sands C. Asthma treatment protocols in the emergency department: are they effective? J Asthma 2007;44:2438.

23. Bekmezian A, Fee C, Weber E. Clinical pathway improves pediatrics asthma management in the emergency department and reduces admissions. J Asthma. 2015;52:806-14.

24. Telreja N, Soubani AO, Sherwin RL, Baptist AP. Modifiable factors associated with severe asthma exacerbations in urban patients. Ann Allergy Asthma Immunil. 2012; 109:128-32

This article is protected by copyright. All rights reserved. 
Table 1: Patient characteristics

\begin{tabular}{|c|c|c|c|c|c|c|}
\hline & $\begin{array}{l}\text { Total } \\
\text { N (\%) }\end{array}$ & $\begin{array}{l}\text { AANZDEM } \\
\mathbf{N}(\%)\end{array}$ & $\begin{array}{l}\text { Missing } \\
\text { data }\end{array}$ & $\begin{array}{l}\text { EuroDEM } \\
\quad \mathbf{N}(\%)\end{array}$ & $\begin{array}{l}\text { Missing } \\
\text { data }\end{array}$ & $p$ value \\
\hline $\mathrm{N}(\%)$ & $584(100)$ & $387(66)$ & - & $197(34)$ & & \\
\hline \multicolumn{7}{|l|}{ Demographics } \\
\hline $\begin{array}{l}\text { Age (years), } \\
\text { (median [Q1-Q3]) }\end{array}$ & $45(30-60)$ & $45[31-60]$ & 1 & $43[27-61]$ & 2 & 0.43 \\
\hline 18-40 years & $236(40)$ & $149(41)$ & - & $87(44)$ & - & 0.53 \\
\hline $41-60$ years & $193(33)$ & $136(35)$ & - & $57(29)$ & - & \\
\hline $61-75$ years & $87(5)$ & $55(14)$ & - & $32(16)$ & - & \\
\hline$>75$ years & $53(9)$ & $36(9)$ & - & $17(9)$ & - & \\
\hline Male (N, \%) & $223(38)$ & $154(40)$ & 1 & $69(35)$ & 0 & 0.30 \\
\hline $\begin{array}{l}\text { Duration of symptoms } \\
\text { (days), (median [Q1- } \\
\text { Q3]) }\end{array}$ & $2[1-4]$ & $2[1-4]$ & 8 & $2[1-7]$ & 24 & 0.16 \\
\hline \multicolumn{7}{|l|}{ Co-morbidities (N, \%) } \\
\hline $\begin{array}{l}\text { Prior history of } \\
\text { asthma }\end{array}$ & $519(89)$ & $351(91)$ & 1 & $168(85)$ & 1 & 0.07 \\
\hline Smoker & $106(18)$ & $62(16)$ & 3 & $44(23)$ & 2 & 0.07 \\
\hline COPD & $32(5)$ & $23(6)$ & 3 & $9(5)$ & 6 & 0.56 \\
\hline \multicolumn{7}{|c|}{ Chronic medication use $(\mathrm{N}, \%)$} \\
\hline $\begin{array}{l}\text { Inhaled beta-2 } \\
\text { agonists }\end{array}$ & $410(70)$ & $289(75)$ & 1 & $121(61)$ & 0 & $<0.001$ \\
\hline $\begin{array}{l}\text { Inhaled } \\
\text { corticosteroids }\end{array}$ & $260(45)$ & $177(46)$ & 0 & $83(42)$ & 0 & 0.43 \\
\hline Oral corticosteroids & $80(14)$ & $52(13)$ & 3 & $28(14)$ & 0 & 0.90 \\
\hline Xanthines & * & $11(3)$ & 3 & $\begin{array}{c}\text { No data } \\
\text { available }\end{array}$ & & \\
\hline Home oxygen & $\begin{array}{c}5(1) \\
\text { missing } \\
\text { data } n=3\end{array}$ & $4(1)$ & 3 & $1(0.5)$ & 0 & 0.67 \\
\hline
\end{tabular}




\begin{tabular}{|c|c|c|c|c|c|c|}
\hline \multicolumn{5}{|c|}{ Mode of arrival $(\mathrm{N}, \%)$} & & \multirow{2}{*}{0.12} \\
\hline By ambulance & $\begin{array}{l}185(32) \\
\text { missing } \\
\text { data } n=9\end{array}$ & $115(30)$ & 5 & $70(36)$ & 4 & \\
\hline
\end{tabular}

*Fisher's exact test

Data are presented as number (percentage) or median (interquartile range).

COPD: chronic obstructive pulmonary disease, PE: pulmonary embolism. 
Table 2: Management at the ED and outcomes

\begin{tabular}{|c|c|c|c|c|c|c|}
\hline & Total & AANZDEM & $\begin{array}{l}\text { Missing } \\
\text { data }\end{array}$ & EuroDEM & $\begin{array}{l}\text { Missing } \\
\text { data }\end{array}$ & $p$ value \\
\hline \multicolumn{7}{|c|}{ Treatment in the ED (N, \%) } \\
\hline Oxygen therapy & $252(44)$ & $155(40)$ & 0 & $97(49)$ & 9 & 0.009 \\
\hline $\begin{array}{l}\text { Inhaled Beta-2 } \\
\text { agonists }\end{array}$ & $504(86)$ & $339(88)$ & 1 & $165(85)$ & 2 & 0.37 \\
\hline $\begin{array}{l}\text { Corticosteroids (IV } \\
\text { or oral) }\end{array}$ & $380(66)$ & $268(69)$ & 1 & $112(58)$ & 3 & 0.006 \\
\hline NIV combined & $13(2.3)$ & $8(2.1)$ & 0 & $5(2.7)$ & 9 & $0.76^{*}$ \\
\hline $\begin{array}{l}\text { Mechanical } \\
\text { ventilation }\end{array}$ & $1(0.2)$ & $0(0)$ & 3 & $1(0.5)$ & 9 & $0.33^{*}$ \\
\hline Antibiotics & $117(20)$ & $89(23)$ & 3 & $28(15)$ & 7 & 0.02 \\
\hline \multicolumn{7}{|c|}{ Discharge from the ED (N, \%) } \\
\hline Home & $385(66)$ & $253(65)$ & 0 & $131(68)$ & 5 & \multirow{4}{*}{$\begin{array}{c}0.64 \\
\text { omnibus } \\
\text { chi } \\
\text { square }\end{array}$} \\
\hline Ward & $180(31)$ & $123(32)$ & 0 & $57(29)$ & 5 & \\
\hline Intensive care unit & $15(2.3)$ & $11(2.8)$ & 0 & $4(2.1)$ & 5 & \\
\hline Death in ED & $0(0)$ & $0(0)$ & 0 & $0(0)$ & 5 & \\
\hline \multicolumn{7}{|c|}{ In hospital outcome (N, \%) } \\
\hline Mortality & $1(0.2)$ & $0(0)$ & 0 & $1(0.5)$ & 8 & $0.34^{*}$ \\
\hline
\end{tabular}

* Fisher's exact test

Data are presented as number (percentage).

ED: emergency department, NIV: non-invasive ventilation, IV: intravenous. 


\section{CONFLICTS OF INTEREST:}

AMK is a member of the ditorial board of EMA. No other Col are declared. Col forms can be provided on request.

\section{AUTHOR CONTRIBUTIONS}

Regarding author contributions: AMK and SL had the concept for the studies, the steering committees contributed to refinement of the protocol, ethics applications, data collection, interpretation of the results and refinement of the manuscript. AMK, SC and WSK performed the analysis and drafted the manuscript.

\section{SOURCES OF FUNDING:}

EuroDEM study was performed under the supervision of the EUSEM Research Committee. Data management in Europe was facilitated by the Jeroen Bosch Hospital.

AANZDEM study was supported by a grant from the Queensland Emergency Medicine Research Foundation, grant number EMPJ-108R21-2014.

\section{SOURCES OF SUPPORT:}

The work of J.M. was supported by the Research Council of Lithuania (grant no. MIP049/2015).

\section{ACKNOWLEDGEMENTS:}

\section{AANZDEM Steering Committee}


Anne Maree Kelly (Chair), Gerben Keijzers (Vice-chair and Queensland), Simon Craig (Victoria), Colin Graham (Hong Kong), Anna Holdgate (NSW), Peter Jones (New Zealand), Win Sen Kuan (Singapore), Said Laribi (France).

AANZDEM Study Group (includes all hospitals that expressed interest in participation, identified a project lead and had ethics approval)

Richard McNulty (Blacktown and Mt Druitt Hospitals NSW), David Lord Cowell (Dubbo Hospital NSW), Anna Holdgate and Nitin Jain (Liverpool Hospital NSW), Tracey de Villecourt (Nepean Hospital NSW), Kendall Lee (Port Macquarie Hospital NSW), Dane Chalkley (Royal Prince Alfred Hospital NSW), Lydia Lozzi (Royal North Shore Hospital NSW), Stephen Asha (St George Hospital NSW), Martin Duffy (St Vincent's Hospital Sydney NSW), Gina Watkins (Sutherland Hospital NSW), David Rosengren (Greenslopes Private Hospital QLD), Jae Thone (Gold Coast Hospital QLD), Shane Martin (Ipswich Hospital QLD), Ulrich Orda (Mt Isa Hospital QLD), Ogilvie Thom (Nambour Hospital QLD), Frances Kinnear and Michael Watson (Prince Charles Hospital QLD), Rob Eley (Princess Alexandra Hospital QLD), Alison Ryan (Queen Elizabeth II Jubilee Hospital QLD), Douglas Morel (Redcliffe Hospital QLD), Jeremy Furyk (Townsville Hospital QLD), Richard Smith (Bendigo Hospital VIC), Michelle Grummisch (Box Hill Hospital VIC), Robert Meek (Dandenong Hospital VIC), Pamela Rosengarten (Frankston Hospital VIC), Barry Chan and Helen Haythorne (Knox Private Hospital VIC), Peter Archer (Maroondah Hospital VIC), Simon Craig and Kathryn Wilson (Monash Medical Centre VIC), Jonathan Knott (Royal Melbourne Hospital VIC), Pexter Ritchie (Sunshine Hospital VIC), Michael Bryant (Footscray Hospital VIC), Stephen MacDonald (Armadale Hospital WA), Mlungisi Mahlangu (Peel Health WA), Peter Jones (Auckland City Hospital New Zealand), Michael Scott (Hutt Valley Hospital New Zealand), 
Thomas Cheri (Palmerston North Hospital New Zealand), Mai Nguyen (Wellington Regional Hospital New Zealand), Colin Graham and Melvin Chor (Prince of Wales Hospital Hong Kong), Chi Pang Wong and Tai Wai Wong (Pamela Youde Nethersole Eastern Hospital Hong Kong), Ling-Pong Leung (Queen Mary Hospital Hong Kong), Chan Ka Man (Tuen Mun Hospital Hong Kong), Ismail Mohd Saiboon (Hospital Universiti Kebangsaan Malaysia, Nik Hisamuddin Rahman (Hospital Universiti Sains Malaysia), Wee Yee Lee (Changi General Hospital Singapore), Francis Chun Yue Lee and Shaun Goh (Khoo Teck Puat Hospital Singapore), Win Sen Kuan (National University Hospital Singapore), Sharon Klim, Kerrie Russell \& Anne-Maree Kelly (AANZDEM co-ordinating centre), Gerben Keijzers, \& Said Laribi (steering committee) and Charles Lawoko (Victoria University, statistician).

\section{EuroDEM Steering Committee:}

Said Laribi (Chair, France), Oene van Meer (the Netherlands), Richard Body (United Kingdom), Mehmet Karamercan (Turkey), Veli-Pekka Harjola (Finland), Adela Golea (Romania), Franck Verschuren (Belgium), Michael Christ (Germany), Cinzia Barletta (Italy) and Luis Garcia-Castrillo (Spain)

\section{EuroDEM Study Group (includes all hospitals that provided data):}

- France: Patrick Plaisance, Ghanima Al Dandachi (CHU Lariboisière, Paris), Maxime Maignan (CHU Grenoble), Dominique Pateron, Christelle Hermand (CHU Saint Antoine, Paris), Cindy Tessier (CHU de Dijon), Pierre-Marie Roy (CHU d'Angers), Lucie Bucco (CH de Chalon sur Saône), Nicolas Duytsche (CH de Macon).

- Spain: Pablo Garmilla (Hospital Universitario Marques Valdecilla).

- Italy: Cinzia Barletta (St Eugenio Hospital, Rome), Giorgio Carbone (Gradenico Hospital, Turin), Roberto Cosentini (Polyclinic Hospital, Milan). 
- Romania: Sorana Truță (Emergency Department of the County Emergency Hospital, Târgu Mureș), Natalia Hrihorișan (Emergency Department of the County Emergency Hospital, Oradea), Diana Cimpoeșu (University of Medicine and Pharmacy, Emergency Department of the University County Emergency Hospital, lași), Luciana Rotaru (University of Medicine and Pharmacy, Emergency Department of the University County Emergency Hospital, Craiova), Alina Petrică (Emergency Department of the County Emergency Hospital, Timișoara), Mariana Cojocaru (Emergency Department of the Emergency Hospital Elias București), Silvia Nica (Emergency Department of the University Emergency Hospital București), Rodica Tudoran (University of Medicine, Emergency Department of the County Emergency Hospital Constanța), Cristina Vecerdi (Emergency Department of the Emergency Hospital Brașov), Monica Puticiu (Emergency Department of the Emergency Hospital Arad).

- The Netherlands: Titus Schönberger (Jeroen Bosch Hospital, Hertogenbosch), Constant Coolsma (Medical Center Leeuwarden, Leeuwarden), Maarten Baggelaar (Canisius Wilhelmina Hospital, Nijmegen), Noortje Fransen (Elisabeth-TweeSteden, Tilburg), Crispijn van den Brand (Haaglanden Medical Center, the Hague), Doutsje Idzenga (Hospital St. Jansdal, Harderwijk), Maaike Maas (Catharina Hospital, Eindhoven), Myriam Franssen (Zuyderland, Heerlen), Charlotte Mackaij - Staal (St. Antonius Hospital, Nieuwegein), Lot Schutte (OLVG, Amsterdam), Marije de Kubber (Leiden University Medical Center, Leiden), Lisette Mignot-Evers (Máxima Medical Center, Eindhoven), Ursula Penninga-Puister (Wilhelmina Hospital, Assen), Joyce Jansen (Academic Medical Center, Amsterdam), Jeroen Kuijten (Elkerliek Hospital, Helmond), Marna Bouwhuis (Erasmus Medical Center, Rotterdam).

This article is protected by copyright. All rights reserved. 
- United Kingdom: Richard Body (Manchester Royal Infirmary), Adam Reuben (Royal Devon and Exeter NHS Foundation Trust), Jason Smith (Plymouth Hospitals NHS Trust), Shammi Ramlakhan (Sheffield Teaching Hospitals), Melanie Darwent (Oxford Radcliffe Hospitals NHS Foundation Trust), James Gagg (Taunton and Somerset NHS Foundation Trust), Liza Keating (Royal Berkshire NHS Foundation Trust), Santosh Bongale ( Inverclyde Hospital), Elaine Hardy (University Hospital Birmingham), Jeff Keep (King's College Hospital NHS Foundation Trust), Heather Jarman (St. George's Healthcare NHS Trust), Steven Crane (York Teaching Hospital NHS Foundation Trust), Olakunle Lawal (Basildon and Thurrock), Taj Hassan (Leeds Teaching Hospitals NHS Foundation Trust), Alasdair Corfield (Royal Alexandra Hospital), Matthew Reed (Infirmary of Edinburgh).

- Germany: Michael Christ, Felicitas Geier, Yvonne Smolarsky (Department of Emergency and Critical Care Medicine, Paracelsus Medical University, Nuremberg), Sabine Blaschke (Department of Emergency Care Medicine, University of Goettingen), Clemens Kill, Andreas Jerrentrup (Department of Emergency Care Medicine, University of Marburg), Christian Hohenstein (Department of Emergency Care Medicine ,University of Jena), Felix Rockmann, Tanja Brünnler (Department of Emergency Care Medicine, Krankenhaus Barmherzige Brüder, Regensburg).

- Belgium: Alexandre Ghuysen (Centre Hospitalier Universitaire de Liège), Marc Vranckx (Centre Hospitalier Universitaire de Charleroi), Franck Verschuren (Cliniques Universitaires Saint-Luc Brussels).

- Turkey: Mehmet A. Karamercan (Gazi University Faculty of Medicine Hospital, Ankara), Mehmet Ergin (Necmettin Erbakan University Meram Faculty of Medicine Hospital, Konya), Zerrin D. Dundar (Necmettin Erbakan University Meram Faculty of 
Medicine Hospital, Konya), Yusuf A. Altuncu (Ege University Faculty of Medicine Hospital, Izmir), Ibrahim Arziman (Gulhane Military Medical Academy Hospital, Ankara), Mucahit Avcil (Adnan Menderes University Medical Faculty Hospital, Aydin), Yavuz Katirci (Ankara Education and Research Hospital, Ankara).

- Finland: Hanna Suurmunne, Liisa Kokkonen (Päijät-Häme Social and Health Care Group, Lahti), Jukka Tolonen, Juha Valli (Helsinki and Uusimaa Hospital District, Hyvinkää), Minna Kiljunen (North Karelia Central Hospital and Honkalampi Centre, Joensuu), Jukka Tolonen (Helsinki University Hospital, Helsinki), Sanna Kaye (City of Helsinki Department of Social Services and Health Care, Helsinki), Jukka Tolonen, Mikko Mäkelä (Helsinki University Hospital, Espoo), Jukka Tolonen, Juhani Metsäniitty (Helsinki University Hospital,Vantaa), Eija Vaula (Satakunta Central Hospital, Pori).

We thank Toine van den Ende and Ans Kluivers for their assistance in collecting data in Europe.

This article is protected by copyright. All rights reserved. 


\section{University Library}

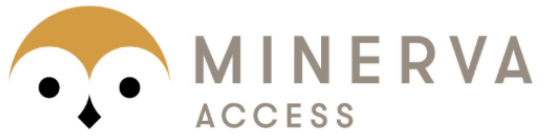

A gateway to Melbourne's research publications

Minerva Access is the Institutional Repository of The University of Melbourne

\section{Author/s:}

Craig, S;Kuan, WS;Kelly, A-M;Van Meer, O;Motiejunaite, J;Keijzers, G;Jones, P;Body,

R;Karamercan, MA;Klim, S;Harjola, V-P;Verschuren, F;Holdgate, A;Christ, M;Golea, A;Graham, CA;Capsec, J;Barletta, C;Garcia-Castrillo, L;Laribi, S

Title:

Treatment and outcome of adult patients with acute asthma in emergency departments in Australasia, South East Asia and Europe: Are guidelines followed? AANZDEM/EuroDEM study

Date:

2019-10-01

\section{Citation:}

Craig, S., Kuan, W. S., Kelly, A. -M., Van Meer, O., Motiejunaite, J., Keijzers, G., Jones, P., Body, R., Karamercan, M. A., Klim, S., Harjola, V. -P., Verschuren, F., Holdgate, A., Christ, M., Golea, A., Graham, C. A., Capsec, J., Barletta, C., Garcia-Castrillo, L. \& Laribi, S. (2019). Treatment and outcome of adult patients with acute asthma in emergency departments in Australasia, South East Asia and Europe: Are guidelines followed? AANZDEM/EuroDEM study. EMERGENCY MEDICINE AUSTRALASIA, 31 (5), pp.756-762. https://doi.org/10.1111/1742-6723.13242.

Persistent Link:

http://hdl.handle.net/11343/285486 